\title{
Noise analysis and optimization of VCII-based SiPM interface circuit
}

\author{
G. Ferri ${ }^{1} \cdot$ L. Safari ${ }^{1} \cdot$ G. Barile ${ }^{1} \cdot$ L. Pantoli ${ }^{1} \cdot$ V. Stornelli ${ }^{1}$
}

Received: 1 December 2019/Revised: 1 September 2020/Accepted: 3 November 2020/Published online: 21 November 2020

(C) The Author(s) 2020

\begin{abstract}
Recently, second generation voltage conveyor (VCII)-based transimpedance amplifiers (TIAs) have begun to find their way in different applications, among which, silicon photomultipliers (SiPMs) interfacing circuitry. There are many advantages which make VCII-based TIAs attractive over conventional circuits: the intrinsic low impedance at VCII current input Y port is very helpful to mitigate the effect of high value sensor capacitance and provides fast response time; the achieved bandwidth is high and due to current mode operation; the circuits enjoy the low-voltage low-power features. As signal-tonoise ratio is a crucial parameter in SiPMs interface circuit applications, here we consider the noise specifications and optimization of VCII-based SiPM interface circuits. The noise model of VCII is introduced and equivalent noise of a VCIIbased interface circuit is derived. Methods to optimize trade-offs existing between key parameters including power consumption, gain and noise performance are discussed. Simulation results are also provided showing a considerable reduction of two orders of magnitude in most of the noise performances when compared to the previous work while preserving other performance parameters.
\end{abstract}

Keywords CCII $\cdot$ Current mode $\cdot$ VCII $\cdot$ Current conveyor

\section{Introduction}

Interesting features such as high photodetection efficiency, robustness, high gain and low-cost has created a high interest in Silicon Photomultiplier detectors (SiPM), which are very promising in different fields of fast timing applications such as medical imaging (TOF-PET) and high energy physics [1-6]. On the other side, SiPMs have drawbacks related to some performance parameters for the dedicated preamplifier. For example, to avoid the reduction in response time caused by high value output capacitance of SiPM, (which exhibits values in the range of hundreds of $\mathrm{pF}[7,8])$, the preamplifier circuit must exhibit very low input impedance. In addition, SiPMs do not behave as an ideal current source and their equivalent output impedance varies by the amount of incident light. Therefore, the low input impedance of the preamplifier is mandatory to keep the nonlinear behavior caused by non-constant output

G. Ferri

giuseppe.ferri@univaq.it

1 Department of Industrial and Information Engineering and Economics, University of L'Aquila, 67100 L'Aquila, Italy impedance of SiPM, as low as possible. Another important parameter of preamplifier is the low noise performance which is crucial to avoid whole system signal-to-noise degradation. Definitively, as the amplitude of SiPM output current is low, the preamplifier should exhibit very low noise feature. Finally, in order to use the full potential of SiPM in achieving fast response time, high frequency performance is another critical parameter in the associated preamplifier. The reduction in the allowed supply voltage in advanced CMOS technologies also puts severe limitations on the preamplifier dynamic range. All these considerations reveal that the design of preamplifier circuit for SiPM is very challenging because there is a need for a careful optimization of trade-offs between input impedance, bandwidth, dynamic range, noise performance and power consumption. Therefore, novel circuit topologies should be developed to relax the downsides of SiPM and fully exploit its desired features.

Recently, with the aim of designing a very effective SiPM preamplifier circuit, a new approach based on second generation voltage conveyor (VCII) has been introduced and its effectiveness has been investigated in literature [9-14]. Especially in [13] a comparative analysis on realizing various analog functions using VCII, CCII and 
operational amplifiers is given. Figure 1(a) reports the symbol of VCII, which is the dual of well-known second generation current conveyor (CCII) [12-14]. Unlike CCII, VCII Y node is a low impedance current input port. The impedance at $\mathrm{Y}$ node is ideally zero, so it can be used as preamplifier input. $\mathrm{X}$ is a high impedance current output or voltage input terminal. The input current at $\mathrm{Y}$ node is transferred to $\mathrm{X}$ node by a current gain $\pm \beta$ very close to unity. $\mathrm{VCII}^{+}$and $\mathrm{VCII}^{-}$are denoted by $+\beta$ and $-\beta$ respectively. The $\mathrm{Z}$ terminal is a low impedance voltage output node. The voltage produced at $X$ terminal is transferred to $\mathrm{Z}$ terminal by a voltage gain $\alpha$ ideally close to unity:

$\beta=\frac{\beta_{0}}{1+\frac{s}{P_{\beta}}}, \alpha=\frac{\alpha_{0}}{1+\frac{s}{P_{\alpha}}}$

being $\beta_{0}$ and $\alpha_{0}$ DC gain values and $P_{\beta}$ and $P_{\alpha}$ the $-3 \mathrm{~dB}$ bandwidths of $\beta$ and $\alpha$ respectively. The operation of VCII based SiPM preamplifier in a transimpedance amplifier (TIA) configuration [10], shown in Fig. 1(b), can be simply explained as follows. The SiPM is connected to the low impedance Y port of VCII. The output current of SiPM entering $\mathrm{Y}$ port is transferred to $\mathrm{X}$ terminal with a gain close to unity. A gain controlling resistor $R_{g}$ is connected to $\mathrm{X}$ terminal. Therefore, the current inside $\mathrm{X}$ terminal of $\mathrm{SiPM}$ is transferred to a proportional voltage at $\mathrm{X}$ node,

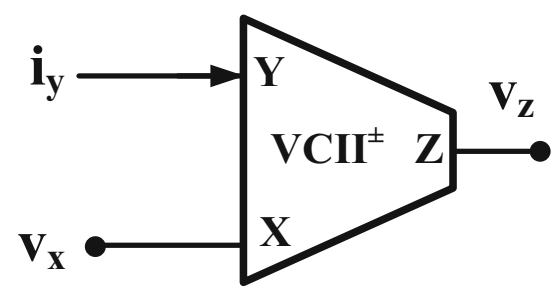

(a)

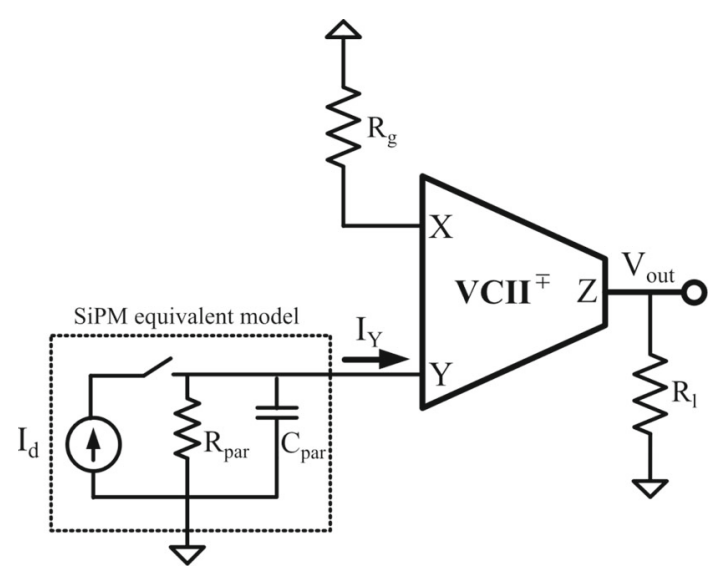

(b)

Fig. 1 VCII a Symbolic representation [12] and b SiPM preamplifier [10] then the produced voltage is transferred to $\mathrm{Z}$ port. Using Eq. (1) the output voltage is found as:

$V_{\text {out }} \approx \pm \frac{\beta_{0} \alpha_{0} R_{g}}{\left(1+\frac{s}{P_{\beta}}\right)\left(1+\frac{s}{P_{\alpha}}\right)\left(1+s R_{g} C_{x}\right)} I_{d}$

being $C_{x}$ the total parasitic capacitance at $\mathrm{X}$ terminal. By assuming $P_{\beta}, P_{\alpha}>>\left(R_{g} C_{x}\right)^{-1}$, Eq. (2) is simplified to:

$V_{\text {out }} \approx \pm \frac{\beta_{0} \alpha_{0} R_{g}}{\left(1+s R_{g} C_{x}\right)} I_{d}$

From Eq. (3), it is found that the bandwidth is determined by the gain controlling resistor $R_{g}$ and parasitic capacitance at $\mathrm{X}$ terminal.

Using VCII based approach to implement SiPM preamplifier, the following benefits are achieved:

(1) The inherent low input impedance at $Y$ port is very effective in mitigating the effect of SiPM parasitic impedance and capacitance effects.

(2) Thanks to the current mode operation, the bandwidth and dynamic range are high.

(3) The bandwidth is high because is mainly determined by gain setting resistor $\mathrm{Rg}$ and the parasitic capacitance at $\mathrm{X}$ terminal. Therefore, high bandwidth is simply achievable by reducing $\mathrm{Cx}$ through a proper circuit design.

In the previously published works [9-11], the response time and frequency performance of VCII based SiPM preamplifier have been investigated. Since the noise is also a very important parameter, in this paper we address the noise performance of a VCII based preamplifier. As VCII is the dual circuit of CCII, for noise calculations, we follow the approach for current conveyor noise analysis presented in [15]. We start by introducing noise sources in VCII block. Using this model, we derive the output equivalent noise of a general VCII based SiPM preamplifier circuit. Then the noise calculations of VCII CMOS implementation are presented. Based on the results of this study, methods to achieve lower noise performance are discussed. The formulas of the preamplifier key parameters including the VCII node impedances and bandwidth are derived. To confirm the presented theory, Spice simulate results are performed. They show that by applying the discussed optimization methods, the noise performance is significantly improved when compared to the previously designed VCII based preamplifier while preserving other parameter values (voltage and current gains, bandwidth and parasitic impedances). The organization of this paper is as follows: In section II, noise model of VCII is introduced and based on this model the output noise of VCII based SiPM preamplifier is established. In Sect. 3, the CMOS implementation of VCII and its performance parameters 
are given. Then, the equivalent noises at its different ports are analyzed. The trade-offs existing between other performance parameters and noise parameter are discussed. Finally, in Sect. 4 simulation results are provided.

\section{Noise analysis of a VCII based SiPM preamplifier}

\subsection{Noise sources of VCII block and VCII based SiPM preamplifier}

Figure 2 shows the noise model of VCII block. Similar to current conveyors [16], VCII is a multiple-port device where each terminal is represented by an equivalent voltage noise and an equivalent current noise. As it will be shown, for a specific application not all but some of the noise sources play more important role compared to other noise sources. This fact simplifies the designer task to consider those critical noise sources in the circuit design. Figure 3 shows the VCII based SiPM preamplifier noise model (being $Z_{p a r}$ the equivalent impedance resulted from parallel connection of $C_{p a r}$ and $R_{p a r}$ ). In this application, $\mathrm{Y}$ port is connected directly to the SiPM which exhibits high output impedance; therefore, the contribution of $\mathrm{Y}$ port equivalent noise voltage to the overall noise performance is negligible. In other words, due to high output impedance of SiPM the current noise produced by $d v^{2}$ Yneq is unimportant; therefore, its effect can be neglected. Due to current buffering action between $\mathrm{Y}$ and $\mathrm{X}$ ports and voltage buffering action between $\mathrm{X}$ and $\mathrm{Z}$ ports, any current noise source at $\mathrm{Y}$ port is transferred to $\mathrm{X}$ port and any noise voltage at $\mathrm{X}$ port is transferred to $\mathrm{Z}$ port. Assuming unity value for $\alpha$ and $\beta$, the output noise voltage of Fig. 3 is calculated as:

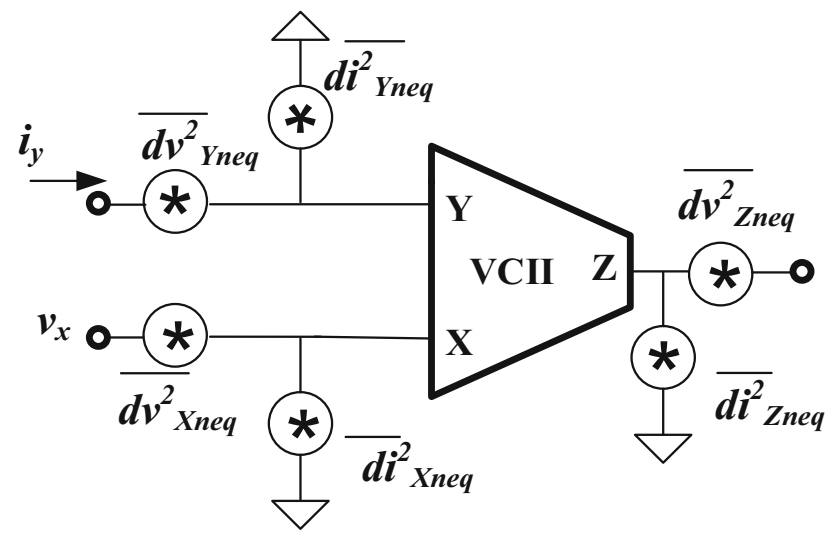

Fig. 2 Noise model of VCII

$$
\begin{aligned}
\overline{d v_{\text {out }}^{2}}= & \left(\overline{d i_{\text {Yneq }}^{2}}+\overline{d i_{\text {Xneq }}^{2}}\right) R_{g}^{2}+\overline{d v_{\text {Xneq }}^{2}}+\overline{d v_{\text {Rg }}^{2}}+\overline{d v_{\text {Zneq }}^{2}} \\
& +\overline{d i_{\text {Zneq }}^{2}} R_{L}^{2}+\overline{d v_{R L}^{2}}
\end{aligned}
$$

The two thermal noise contributions of $R g$ and $R_{L}$ are respectively: $\overline{d v_{R g}^{2}}=4 k T R_{g} d f$ and $\overline{d v_{R L}^{2}}=4 k T R_{L} d f$, where $k$ is Boltzmann constant, $T$ is absolute temperature, $d f$ is frequency bandwidth. In Eq. (4), it is assumed that $R_{g-}$ $<<R_{X}$ and $R_{Z}<<R_{L}$

\subsection{Noise calculation of VCII circuit}

For noise analysis we consider the VCII CMOS implementation of Fig. 4 which has been used in [10] to implement a SiPM preamplifier. In this circuit the negative feedback loop established by differential pair $M_{1}-M_{4}$ is used to reduce the impedance at $\mathrm{Y}$ port and to clamp $V_{Y}$ at ground. The current at $\mathrm{Y}$ port is transferred to $\mathrm{X}$ port by means of simple current mirror made of $M_{6}-M_{7}$. The voltage produced at $\mathrm{X}$ port is transferred to $\mathrm{Z}$ port through a simple flipped voltage follower (FVF) [17] based voltage buffer made of $M_{9}-M_{10}$.

$M_{8}$ is used to set the DC offset voltage at $\mathrm{Z}$ port equal to zero. The small signal equivalent circuit of Fig. 4 is shown in Fig. 5 where, $\mathrm{ro}_{\mathrm{i}}$ and $\mathrm{gm}_{\mathrm{i}}$ denotes the output impedance and transconductance of related transistor. Also, $\mathrm{rO}_{\mathrm{IBi}}$ denotes the output impedance of related current source. Using the presented small signal model, the simplified formulas of impedances at $\mathrm{Y}, \mathrm{X}$ and $\mathrm{Z}$ ports as well as those for $\alpha_{0}$ and $\beta_{0}$ are expressed as respectively:

$r_{y} \approx\left[g_{2} g m_{5} \bullet\left(\mathrm{ro}_{2} / / \mathrm{ro}_{4}\right)\right]^{-1}$

$r_{x} \approx r o_{I B 3} / / r o_{7}$

$r_{Z} \approx\left[g m_{9} g m_{10} r o_{I B 4}\right]^{-1}$

$\alpha_{0} \approx \frac{r o_{7}}{r o_{7}+g m_{8}^{-1}}$

$\beta_{0} \approx \frac{g m_{7}}{g m_{6}}$

In Eq. (5), pair wise matching between differential pair transistors is assumed.

Figure 6 shows the noise model of VCII circuit of Fig. 4 where the noise produced by each MOS transistor is presented as a current source connected in parallel to it. For proper noise calculation, in Fig. 6, the implementation of current sources IB1-IB4 by means of simple current mirrors are also shown. The transistor noise includes $1 / \mathrm{f}$ and channel thermal noise.

The contribution of $1 / \mathrm{f}$ noise on the overall wide bandwidth noise is negligible, therefore the output current noise of the ith transistor is approximated as thermal noise [16]: 
Fig. 3 Noise model of VCII based SiPM preamplifier

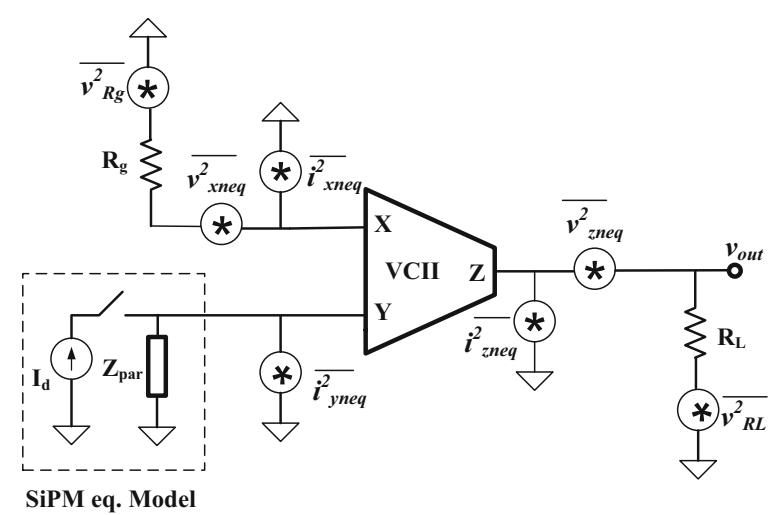

Fig. 4 CMOS implementation of VCII [10]

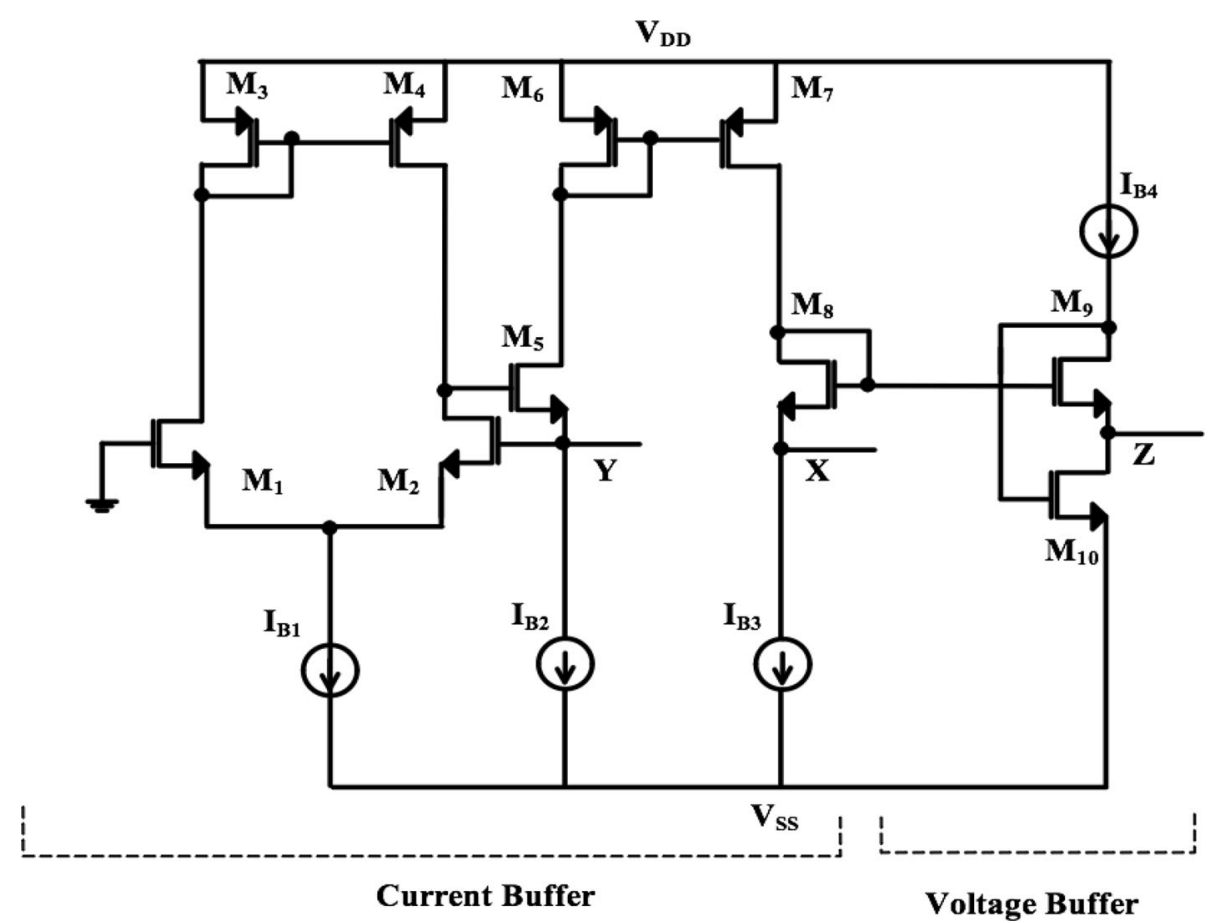


Fig. 5 Small signal equivalent circuit of Fig. 4

Fig. 6 VCII CMOS circuit with noise sources

$\overline{d i_{n i}^{2}}=4 k T \gamma g m_{i} d f$

where $k$ is Boltzmann's constant, $T$ is absolute temperature, $d f$ is frequency bandwidth, $\gamma$ is a constant coefficient ranging from $1 / 3$ to $2 / 3$ and $g m_{i}$ is the transconductance of the ith transistor.

The noise contribution of differential pair made of $M_{1^{-}}$ $M_{4}$ is a noise voltage at $\mathrm{Y}$ port expressed as:

$\overline{d v_{M 1-M 4}^{2}} \mid a t Y \approx 4 \frac{\overline{d i_{n 1}^{2}}+\overline{d i_{n 2}^{2}}+\overline{d i_{n 3}^{2}}+\overline{d i_{n 4}^{2}}}{g_{m}{ }^{2}}$

being $g_{m 1}=g_{m 2}=g_{m}$.

The noise contribution of current source $I_{B 1}$ is negligible. The reason is that the output noise produced by $I_{B 1}$ is attenuated by differential pair as a common mode signal. Transistor $M_{5}$ also produces noise voltage at $\mathrm{Y}$ port equal to:

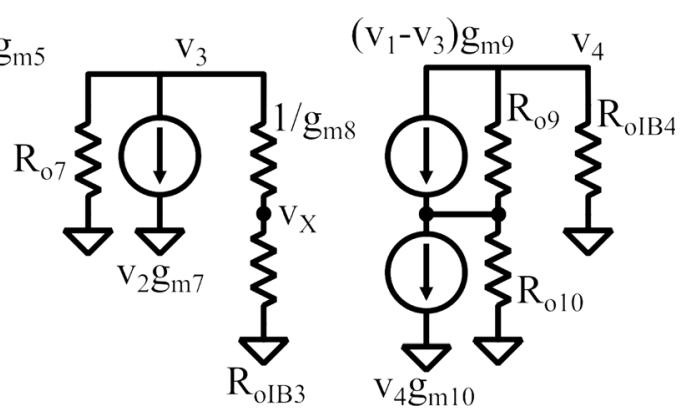

$\overline{\mathrm{di}^{2}}{ }_{\mathrm{nMB5}}$

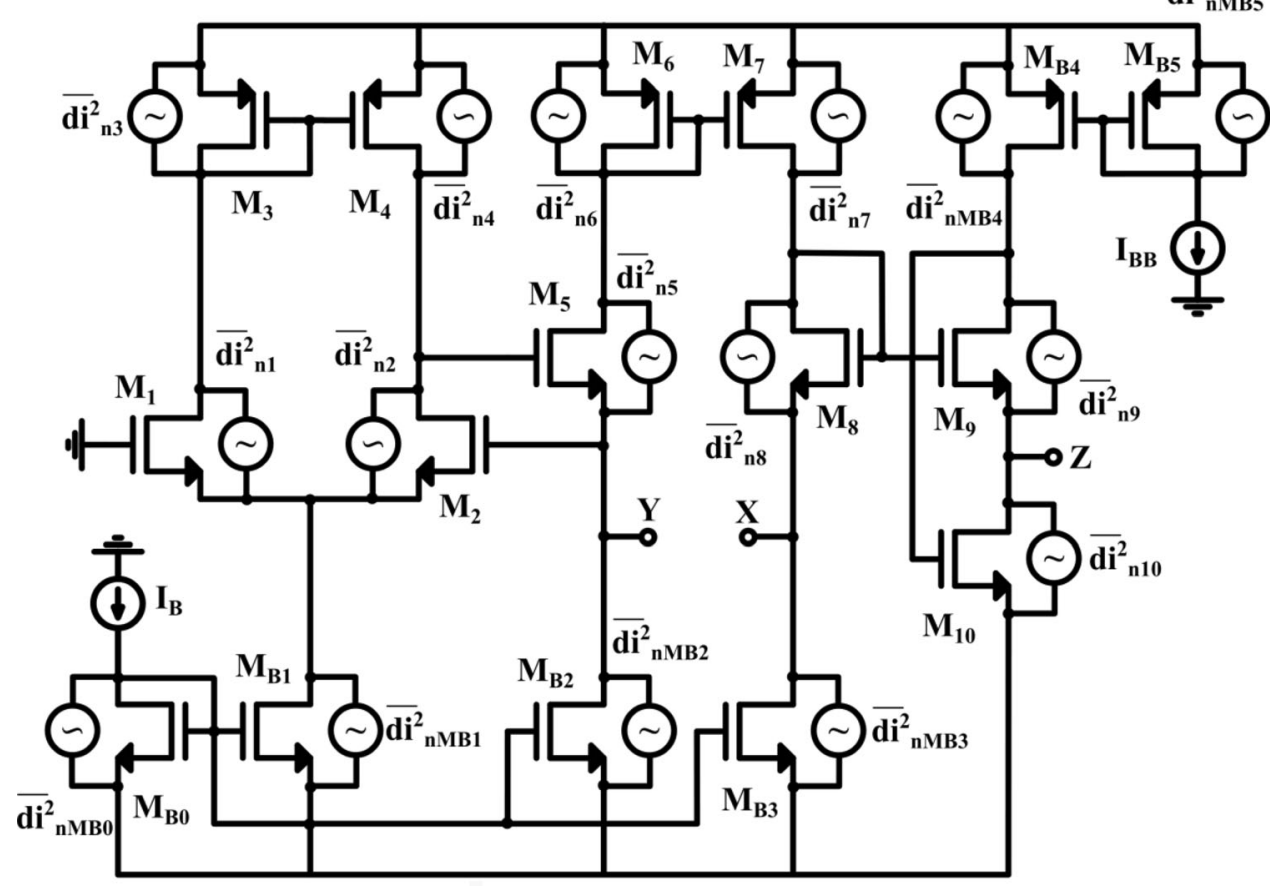

$\overline{d v_{M 5}^{2}} \mid a t Y=\frac{\overline{d i_{n 5}^{2}}}{g_{m 5}{ }^{2} g_{m}^{2}\left(r_{o 2} \| r_{o 4}\right)^{2}}$

Using Eq. (11) and Eq. (12), the total noise voltage at $\mathrm{Y}$ port is:

$\begin{aligned} \overline{d v_{\text {yneq }}^{2}} & =\overline{d v_{M 1-M 4}^{2}} \mid \text { at } Y+\overline{d v_{M 5}^{2}} \mid a t Y \\ & \approx \frac{4 k T \gamma}{g m_{1}^{2}}\left[4 g m_{1}+4 g m_{2}+4 g m_{3}+4 g m_{4}+\frac{1}{g_{m 5}\left(r_{o 2} \| r_{o 4}\right)^{2}}\right] d f\end{aligned}$

From Eq. (13), it is seen that increasing $g m_{2}$ reduces the equivalent current noise voltage at $\mathrm{Y}$ port. From Eq. (5), the impedance at $\mathrm{Y}$ terminal is also improved by increasing $g m_{2}$.

Considering the relationship between bias current and overdrive voltage with $g m_{2}$ represented in Eq. (14), reveals that the allowed supply voltage and the required power consumption set a limit on the maximum value of $g m_{2}$, 
because increasing $g m_{2}$ demands high value for $I_{B 2}$ and consequently the high value of overdrive voltage $V_{G S 2}-V_{T H}$ is required to keep $M_{1}-M_{4}$ in saturation region. Equation (14) shows also the well-known alternative representation of $\mathrm{gm}_{2}$ in terms of transistor aspect ratios and bias currents in strong inversion. After setting the value of $I_{B 1}$ based on circuit power budget, the value of $g m_{2}$ can be increased by selecting large values for $M_{1}-M_{2}$ aspect ratios. By this, although the parasitic capacitance associated with $\mathrm{Y}$ port will increase, but due to the concurrent reduction in $\mathrm{Y}$ port impedance, the effect of increasing aspect ratio of $M_{1}-M_{2}$ on the frequency performance will be negligible. It is worth mentioning that the transistors size increase must not push them in weak inversion region:

$g m_{2}=\frac{2 I_{B 1}}{V_{G S 2-} V_{T H 2}}=\sqrt{I_{B 1} \mu_{n} C_{o x} \frac{W_{2}}{L_{2}}}$

The noise contribution of $M_{5}$ is a voltage at $\mathrm{Y}$ port equal to:

$\overline{d v_{M 5}^{2}}=\frac{\overline{d i_{n 5}^{2}}}{A^{2} g_{m 5}^{2}}=\frac{4 k T \gamma d f}{A^{2} g_{m 5}}$

where, by assuming pair wise matching between differential amplifier transistors (i.e. $M_{1}$ to $M_{2}$ and $M_{3}$ to $M_{4}$ ), $A$ is:

$A \approx g_{m}\left(\mathrm{ro}_{4} \| r \mathrm{O}_{2}\right)$

being $\mathrm{gm}$ the transconductance of $M_{1}-M_{2}$. According to Eq. (15) and Eq. (16), to reduce the noise contribution of $M_{5}$, its $g m$ value should be high. It is remarkable that the noise voltage at $\mathrm{Y}$ node does not contribute to the total output noise of the TIA (see Eq. (4)).

The equivalent current noise at $\mathrm{Y}$ port is expressed as:

$$
\begin{aligned}
\overline{d i_{\text {Yneq }}^{2}} & =\overline{d i_{n 6}^{2}}+\overline{d i_{n I B 2}^{2}}=\overline{d i_{n 6}^{2}}+\overline{d i_{n M B 2}^{2}}+\overline{d i_{n M B 0}^{2}} \\
& =4 k T \gamma\left(g m_{6}+g m_{B 2}+g m_{B 0}\right) d f
\end{aligned}
$$

As $M_{6}$ is a PMOS transistor, its produced channel noise is lower. It is also worth mentioning that as there is good matching between transistors with large aspect ratios $[18,19]$, according to Eq. (9), to keep the value of $\beta_{O}$ at unity, large aspect ratios must be set for $M_{6}-M_{7}$. This will increase the parasitic capacitances associated with these transistors. However, as the input impedance of current mirror $M_{6}-M_{7}$ will reduce by increasing their aspect ratios, the effect on overall bandwidth will be partly compensated. In addition, referring to Eq. (8), to keep the $\alpha_{0}$ close to unity, large value is required for $\mathrm{ro}_{7}$ which can be set by increasing channel length or reducing its bias current. However, the required dynamic range sets a limit on the minimum value of bias current. The noise produced by current source $I_{B 2}$ can be made negligible by setting the $\mathrm{gm}$ of the related transistors as low as possible.

The equivalent current noise at $\mathrm{X}$ port is:

$$
\begin{aligned}
\overline{d i_{X n e q}^{2}} & =\overline{d i_{n 7}^{2}}+\overline{d i_{n I B 3}^{2}}=\overline{d i_{n 7}^{2}}+\overline{d i_{n M B 3}^{2}}+\overline{d i_{n M B 0}^{2}} \\
& =4 k T \gamma\left(g m_{7}+g m_{B 3}+g m_{B 0}\right) d f
\end{aligned}
$$

Similar considerations can be done for this result.

The equivalent voltage noise at $\mathrm{X}$ port is also obtained as:

$\overline{d v_{X n e q}^{2}}=\frac{\overline{d i_{n 8}^{2}}}{g m_{8}^{2}}+\frac{\overline{d i_{n 9}^{2}}}{g m_{9}^{2}}==4 k T \gamma\left(g m_{8}{ }^{-1}+g m_{9}{ }^{-1}\right) d f$

As Eq. (19) implies, choosing large values for $g m_{8}$ and $g m_{9}$, the noise voltage at $\mathrm{X}$ terminal is reduced. In the circuit of Fig. 6, the same noise voltage at $\mathrm{X}$ node is produced at $\mathrm{Z}$ terminal.

The expression for noise current at $\mathrm{Z}$ port is:

$$
\begin{aligned}
\overline{d i_{Z n e q}^{2}} & =\overline{d i_{n 10}^{2}}+\overline{d i_{n I B 4}^{2}}=\overline{d i_{n 10}^{2}}+\overline{d i_{n M B 4}^{2}}+\overline{d i_{n M B 5}^{2}} \\
& =4 k T \gamma\left(g m_{10}+g m_{B 4}+g m_{B 5}\right) d f
\end{aligned}
$$

As the $M_{B 4}-M_{B 5}$ are PMOS transistors which inherently produce low noise compared to NMOS transistors, the effective method to reduce current noise at $\mathrm{Z}$ output is reducing the value of $g_{m 10}$. To avoid increasing the impedance at $\mathrm{Z}$ port due to the reduction of $g_{m 10}$, the output impedance of $I_{B 3}$ current source should be increased by choosing large values for the channel length of transistor $M_{B 4}-M_{B 5}$.

\section{Simulations}

The VCII circuit of Fig. 4 is simulated using Spice and $0.35 \mu \mathrm{m}$ CMOS technology with a supply voltage of \pm $1.65 \mathrm{~V}$. The approach we used to optimize noise performances is given in Table 1. Table 2 shows the new values for transistors' aspect ratios along with the former ones from [10]. A comparison between pre and post optimization VCIIs is given in Table 3 where noise sources at Y, X and $\mathrm{Z}$ ports as well as other performance parameters are given.

As it is stated in Table 2, the major increase in aspect ratio is equal to 10 times related to $\mathrm{M}_{1}-\mathrm{M}_{2}$ and $\mathrm{M}_{5}$, so we expect approximately $30 \%$ increase in the used area. However, investigating the achieved noise results at Table 3 shows a 51 times reduction for noise current at $\mathrm{Y}$ node, a 121 times reduction for noise current at $\mathrm{X}$, a 105 times reduction for noise voltage at $\mathrm{X}$, a 58 times reduction for noise current at $\mathrm{Z}$ and a 107 times reduction for noise voltage at $\mathrm{Z}$ while the increase in power consumption is only $52 \mu \mathrm{W}$ and other performance parameters remain rather unchanged. We added these points in the simulation results.

The output noise of the VCII based preamplifier (Fig. 1b), expressed by Eq. (4) is shown in Fig. 7 after and 
Table 1 Noise reduction cause-effect table

\begin{tabular}{lll}
\hline Equation & Cause & Effect \\
\hline$(17-18)$ & Reduction of the transconductance of MB0, MB2 and M6 by decreasing W/L & Reduction in the current noise at Y and X terminals \\
$(19)$ & Increment of the transconductance of M8, and M9 by increasing W/L & Reduction in the voltage noise at X terminal \\
$(20)$ & Reduction of the transconductance of M10 by decreasing W/L & Reduction in the current noise at Z terminal \\
\hline
\end{tabular}

Table 2 Transistors aspect ratio and current source values of the VCII before [10] and after optimization

\begin{tabular}{|c|c|c|c|c|c|}
\hline \multirow[t]{2}{*}{ Transistors } & \multicolumn{2}{|l|}{ Dimensions } & \multirow[t]{2}{*}{ Current sources } & \multicolumn{2}{|l|}{ Value } \\
\hline & Standard design & Optimized design & & Standard design & Optimized design \\
\hline $\mathrm{M}_{1}, \mathrm{M}_{2}$ & $\mathrm{~W}=21 \mu \mathrm{m}, \mathrm{L}=0.35 \mu \mathrm{m}$ & $\mathrm{W}=210 \mu \mathrm{m}, \mathrm{L}=0.35 \mu \mathrm{m}$ & $\mathrm{I}_{\mathrm{B}}$ & $30 \mu \mathrm{A}$ & $30 \mu \mathrm{A}$ \\
\hline $\mathrm{M}_{3}, \mathrm{M}_{4}$ & $\mathrm{~W}=4.2 \mu \mathrm{m}, \mathrm{L}=0.35 \mu \mathrm{m}$ & $\mathrm{W}=4.2 \mu \mathrm{m}, \mathrm{L}=0.35 \mu \mathrm{m}$ & $\mathrm{I}_{\mathrm{BB}}$ & $40 \mu \mathrm{A}$ & $40 \mu \mathrm{A}$ \\
\hline $\mathrm{M}_{5}$ & $\mathrm{~W}=7 \mu \mathrm{m}, \mathrm{L}=0.35 \mu \mathrm{m}$ & $\mathrm{W}=210 \mu \mathrm{m}, \mathrm{L}=0.35 \mu \mathrm{m}$ & & & \\
\hline $\mathrm{M}_{6}, \mathrm{M}_{7}$ & $\mathrm{~W}=72.8 \mu \mathrm{m}, \mathrm{L}=4.6 \mu \mathrm{m}$ & $\mathrm{W}=11.2 \mu \mathrm{m}, \mathrm{L}=4.6 \mu \mathrm{m}$ & & & \\
\hline $\mathrm{M}_{8}, \mathrm{M}_{9}$ & $\mathrm{~W}=28.7 \mu \mathrm{m}, \mathrm{L}=1.4 \mu \mathrm{m}$ & $\mathrm{W}=50.05 \mu \mathrm{m}, \mathrm{L}=0.7 \mu \mathrm{m}$ & & & \\
\hline $\mathrm{M}_{10}$ & $\mathrm{~W}=14 \mu \mathrm{m}, \mathrm{L}=52 \mu \mathrm{m}$ & $\mathrm{W}=14 \mu \mathrm{m}, \mathrm{L}=80.15 \mu \mathrm{m}$ & & & \\
\hline $\mathrm{M}_{\mathrm{B} 0}, \mathrm{M}_{\mathrm{B} 1}$ & $\mathrm{~W}=2.1 \mu \mathrm{m}, \mathrm{L}=0.7 \mu \mathrm{m}$ & $\mathrm{W}=0.7 \mu \mathrm{m}, \mathrm{L}=0.7 \mu \mathrm{m}$ & & & \\
\hline $\mathrm{M}_{\mathrm{B} 2}, \mathrm{M}_{\mathrm{B} 3}$ & $\mathrm{~W}=2.8 \mu \mathrm{m}, \mathrm{L}=0.7 \mu \mathrm{m}$ & $\mathrm{W}=1.05 \mu \mathrm{m}, \mathrm{L}=0.7 \mu \mathrm{m}$ & & & \\
\hline $\mathrm{M}_{\mathrm{B} 4}, \mathrm{M}_{\mathrm{B} 5}$ & $\mathrm{~W}=132.3 \mu \mathrm{m}, \mathrm{L}=42 \mu \mathrm{m}$ & $\mathrm{W}=133 \mu \mathrm{m}, \mathrm{L}=42 \mu \mathrm{m}$ & & & \\
\hline
\end{tabular}

Table 3 Performance and noise parameters of the VCII (Left) and open loaded TIA (Right) before [10] and after optimization

\begin{tabular}{|c|c|c|c|c|c|}
\hline \multirow[t]{2}{*}{ Parameter } & \multicolumn{2}{|l|}{ Value } & \multirow[t]{2}{*}{ Noise source } & \multicolumn{2}{|c|}{ Value (@100kHz) } \\
\hline & Standard design & Optimized design & & Standard design & Optimized design \\
\hline ry & $49 \Omega$ & $106 \Omega$ & Inoise at $\mathrm{Y}$ & $220 \mathrm{pA} / \sqrt{ } \mathrm{Hz}$ & $4.3 \mathrm{pA} / \sqrt{ } \mathrm{Hz}$ \\
\hline $\mathrm{Rx}$ & $802 \mathrm{k} \Omega$ & $622 \mathrm{k} \Omega$ & Vnoise at $\mathrm{Y}$ & $10.5 \mathrm{nV} / \sqrt{\mathrm{Hz}}$ & $9.3 \mathrm{nV} / \sqrt{\mathrm{Hz}}$ \\
\hline$r z$ & $79 \Omega$ & $380 \Omega$ & Inoise at $\mathrm{X}$ & $219 \mathrm{pA} / \sqrt{ } \mathrm{Hz}$ & $1.8 \mathrm{pA} / \sqrt{\mathrm{Hz}}$ \\
\hline$\left(\alpha_{0}, P_{\alpha}\right) \alpha$ & $0.995,340 \mathrm{MHz}$ & $0.994,483 \mathrm{MHz}$ & Vnoise at $\mathrm{X}$ & $3 \mu \mathrm{V} / \sqrt{ } \mathrm{Hz}$ & $28.4 \mathrm{nV} / \sqrt{ } \mathrm{Hz}$ \\
\hline$\left(\beta_{0}, P_{\beta}\right) \beta$ & $0.996,14.6 \mathrm{MHz}$ & $0.978,21 \mathrm{MHz}$ & Inoise at $\mathrm{Z}$ & $280 \mathrm{pA} / \sqrt{ } \mathrm{Hz}$ & $4.8 \mathrm{pA} / \sqrt{\mathrm{Hz}}$ \\
\hline Static power dissipation & $700 \mu \mathrm{W}$ & $752 \mu \mathrm{W}$ & Vnoise at $\mathrm{Z}$ & $2.9 \mu \mathrm{V} / \sqrt{ } \mathrm{Hz}$ & $27 \mathrm{nV} / \sqrt{ } / \mathrm{Hz}$ \\
\hline
\end{tabular}

before optimization. As it is seen, in agreement with Table 3 , it is reduced from $3.2 \mu \mathrm{V} / \sqrt{ } \mathrm{Hz}$ to $29.9 \mathrm{nV} / \sqrt{ } / \mathrm{Hz}$ (@ $100 \mathrm{kHz}$ ) in the optimized circuit. The frequency performance of VCII-based preamplifier for different values of $\mathrm{Rg}$ is also shown in Fig. 8. As it is seen, the applied optimization does not have significant effect on the frequency performance.

\section{Conclusions}

In this paper we address the noise model and performance of VCII-based SiPM preamplifier. As a multi-port device, each port is modeled by an equivalent voltage and current noise. It is discussed that due to the high output impedance of SiPM, the equivalent noise voltage at Y port does not contribute to the overall noise performance of VCII based preamplifier. However, both equivalent current and voltage noises at $\mathrm{X}$ port are transferred to the output and play an important role on the determining noise at preamplifier output port. 


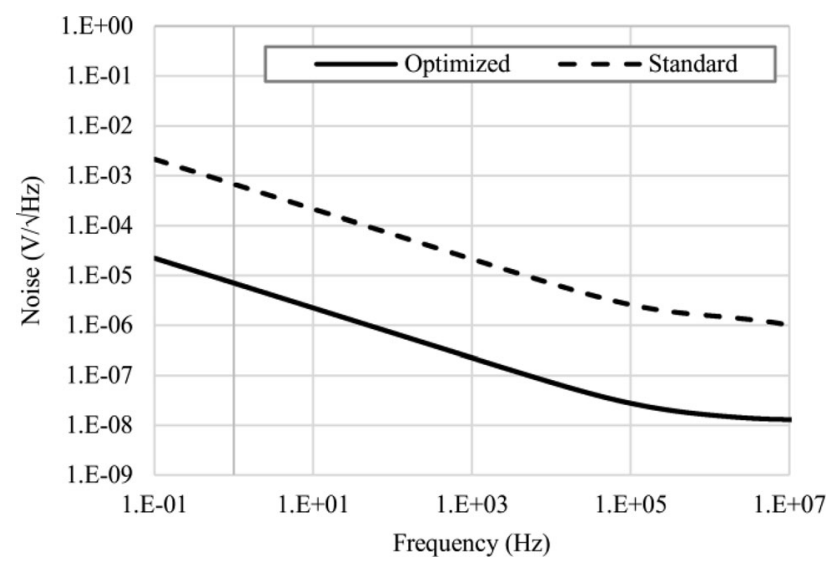

Fig. 7 The output noise of the VCII based preamplifier after and before optimization

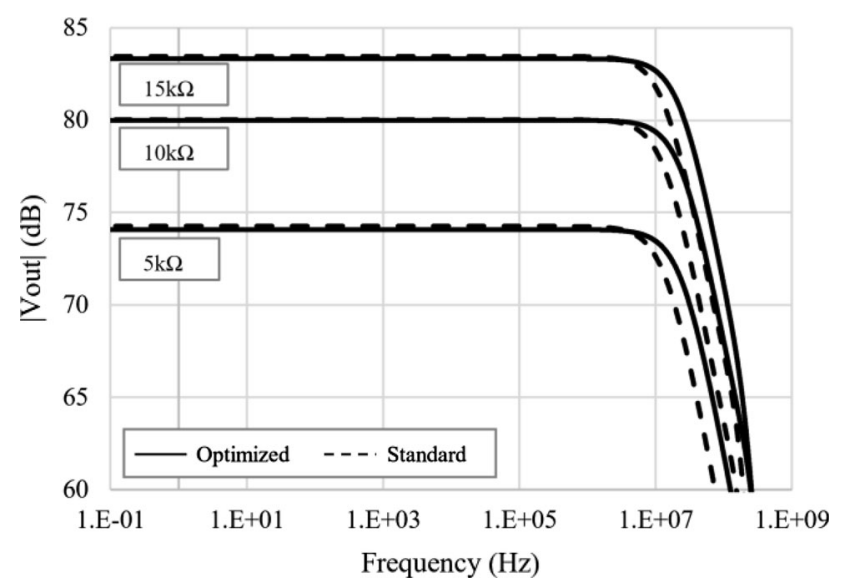

Fig. 8 The frequency performance of the VCII based preamplifier after and before optimization

Funding Open access funding provided by Università degli Studi dell'Aquila within the CRUI-CARE Agreement.

Open Access This article is licensed under a Creative Commons Attribution 4.0 International License, which permits use, sharing, adaptation, distribution and reproduction in any medium or format, as long as you give appropriate credit to the original author(s) and the source, provide a link to the Creative Commons licence, and indicate if changes were made. The images or other third party material in this article are included in the article's Creative Commons licence, unless indicated otherwise in a credit line to the material. If material is not included in the article's Creative Commons licence and your intended use is not permitted by statutory regulation or exceeds the permitted use, you will need to obtain permission directly from the copyright holder. To view a copy of this licence, visit http://creativecommons. org/licenses/by/4.0/.

\section{References}

1. Huizenga, J., et al. (2012). A fast preamplifier concept for SiPMbased time-of-flight PET detectors. Nuclear Instruments and Methods in Physics Research Section A: Accelerators,
Spectrometers, Detectors and Associated Equipment, 695, 379-384. https://doi.org/10.1016/j.nima.2011.11.012.

2. Corsi F., et al., "Electrical characterization of silicon photomultiplier detectors for optimal front-end design", In 2006 IEEE Nuclear Science Symposium Conference Record, San Diego, CA, USA, 2006, pp. 1276-1280. https://doi.org/10.1109/NSSMIC. 2006.356076.

3. Powolny, F., et al. (2011). Time-based readout of a silicon photomultiplier (SiPM) for time of flight positron emission tomography (TOF-PET). IEEE Transactions on Nuclear Science, 58(3), 597-604. https://doi.org/10.1109/tns.2011.2119493.

4. Salvador, B., Pineda, E. D. A., Fernandez-Maza, L., Corral, A., Camacho-Leon, S., \& Luque, A. (2019). Monitoring of microfluidics systems for PET radiopharmaceutical synthesis using integrated silicon photomultipliers. IEEE Sensors Journal, 19(17), 7702-7707. https://doi.org/10.1109/JSEN.2019.2917362.

5. Ren, M., Zhou, J., Yang, S., Zhuang, T., Dong, M., \& Albarracín, R. (2018). Optical partial discharge diagnosis in SF6 gas-insulated system with SiPM-based sensor array. IEEE Sensors Journal, 18(13), 5532-5540. https://doi.org/10.1109/JSEN.2018. 2836423.

6. Garutti, E. (2011). Silicon photomultipliers for high energy physics detectors. Journal of Instrumentation, 6(10), C10003C10003. https://doi.org/10.1088/1748-0221/6/10/c10003.

7. Oliveira, L., Leitao, C., \& Silva, M. (2012). Noise performance of a regulated cascode transimpedance amplifier for radiation detectors. IEEE Transactions on Circuits and Systems I: Regular Papers, 59(9), 1841-1848. https://doi.org/10.1109/tcsi.2011. 2180449.

8. Bonanno, G., et al. (2014). Characterization measurements methodology and instrumental set-up optimization for new SiPM detectors-Part I: Electrical tests. IEEE Sensors Journal, 14(10), 3557-3566. https://doi.org/10.1109/JSEN.2014.2328621.

9. Barile G., Leoni A., Pantoli L., Safari L. and Stornelli V., “A new VCII based low-power low-voltage front-end for silicon photomultipliers", in 2018 3rd International Conference on Smart and Sustainable Technologies (SpliTech), Split, Croatia, 2018.

10. Pantoli, L., Barile, G., Leoni, A., Muttillo, M., \& Stornelli, V. (2018a). A novel electronic interface for micromachined Si-based photomultipliers. Micromachines, 9(10), 507. https://doi.org/10. 3390/mi9100507.

11. Pantoli, L., Barile, G., Leoni, A., Muttillo, M., \& Stornelli, V. (2018b). "A low-power interface for silicon photomultipliers", sensors \& actuators congress (SAC) 2018. Sweden: Stockholm.

12. Safari, L., Barile, G., Stornelli, V., \& Ferri, G. (2019). An overview on the second generation voltage conveyor: Features, design and applications. IEEE Transactions on Circuits and Systems II: Express Briefs, 66(4), 547-551. https://doi.org/10. 1109/tcsii.2018.2868744.

13. Safari, L., Barile, G., Ferri, G., \& Stornelli, V. (2019). Traditional Op-Amp and new VCII: A comparison on analog circuits applications. AEU - International Journal of Electronics and Communications, 110, 152845. https://doi.org/10.1016/j.aeue.2019. 152845.

14. Barile, G., Ferri, G., Safari, L., \& Stornelli, V. (2019). A new high drive class-AB FVF based second generation voltage conveyor. IEEE Transactions on Circuits and Systems II: Express Briefs. https://doi.org/10.1109/tcsii.2019.2915814.

15. Ferri, G., \& Guerrini, N. (2004). Noise determination in differential-pair based second generation current conveyors. Analog Integrated Circuits and Signal Processing, 41(1), 35-46.

16. Bruun E., Noise properties of CMOS current conveyors, in 1996 IEEE International Symposium on Circuits and Systems. Circuits and Systems Connecting the World. ISCAS 96, Atlanta, GA, USA, 1996, pp. 1276-1291. https://doi.org/10.1109/ISCAS.1996. 539829. 
17. Carvajal, R., et al. (2005). The flipped voltage follower: A useful cell for low-voltage low-power circuit design. IEEE Transactions on Circuits and Systems I: Regular Papers, 52(7), 1276-1291. https://doi.org/10.1109/tcsi.2005.851387.

18. Koli K. CMOS current amplifiers: Speed versus nonlinearity, Helsinki University of Technology Electronic Circuit Design Laboratory, Report 30, Espoo 2000.

19. Bruun, E. (1998). Worst case estimate of mismatch induced distortion in complementary CMOS current mirrors. Electronics Letters. https://doi.org/10.1049/el:19981150.

Publisher's Note Springer Nature remains neutral with regard to jurisdictional claims in published maps and institutional affiliations.

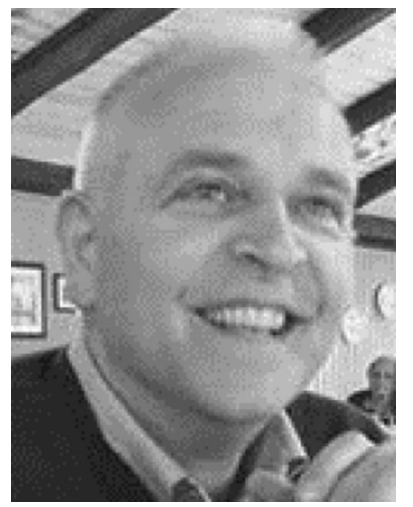

Giuseppe Ferri was born in L'Aquila, Italy. He received the "Laurea" degree (cum laude) in electronic engineering in 1988. In 1991, he joined the Department of Electronic Engineering, University of L'Aquila, L'Aquila, Italy, where he is actually a full professor of Electronics and Microelectronics. His research activity mainly concerns the design of analog electronic circuits for integrated sensor applications both in voltage and in current-mode. In this field of research, he is author or coauthor of 7 patents, 3 international books, one book chapter and about 400 publications in international journals and conference proceedings. He is an IEEE senior member and Editor of Sensors and of Journal of Circuits, Computers and Systems.

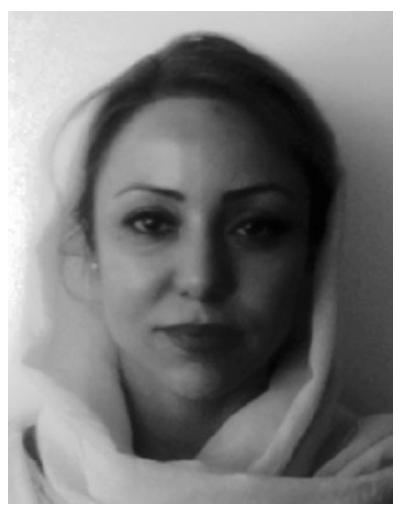

Leila Safari received the master's degree in electrical engineering from the Iran University of Science and Technology (IUST) in Islamic Republic of Iran, where she also received her Ph.D. from. She is currently area Editor of International Journal of Electronics and Communications-AEUE and reviewer of ISI Journals and IEEE conferences. Her research activity revolves around CMRR optimization in CMOS and BJT OpAmps, study on currentmode circuits, design of current-mode and mixed-mode integrated circuits and design of industrial systems.

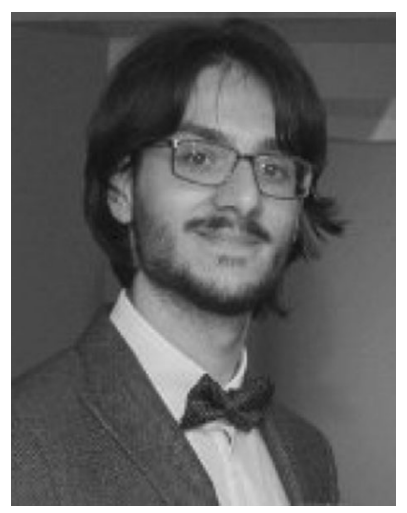

Gianluca Barile was born in Avezzano, Italy. He received the master's degree (cum laude) in Electronics Engineering from the University of L'Aquila (Italy) in 2016, where $\mathrm{He}$ received his Ph.D. degree (cum laude) in 2020. His research interests revolve around discrete and integrated electronic interfaces for sensors, autonomous sensor networks, low-voltage low-power integrated circuits, current-mode readout techniques, electronics for industrial

applications.

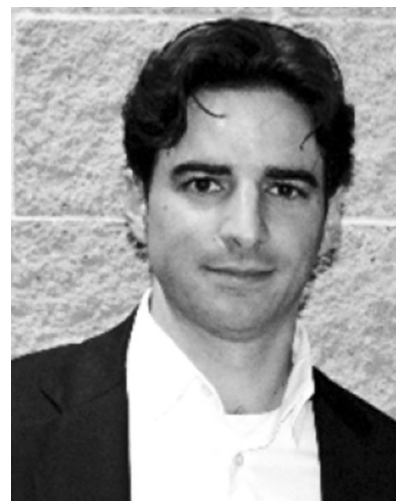

Leonardo Pantoli (M'09) received the Degree (cum laude) in Electronic Engineering and the Ph.D. in Electrical and Information Engineering from the University of L'Aquila, L'Aquila, Italy, in 2006 and 2010, respectively. In 2007 and 2008, he spent several months with the Communications Engineering Department of University of Cantabria, Spain and the C2S2 Department of the XLIM Research Institute, Brive $\mathrm{La}$ Gaillarde, France. $\mathrm{He}$ is Researcher with the University of L'Aquila and his research activities include the development of design methods for microwave nonlinear circuits, linear and nonlinear stability analysis, electronic interfaces for SiPMs and MMICs design for space and communication.

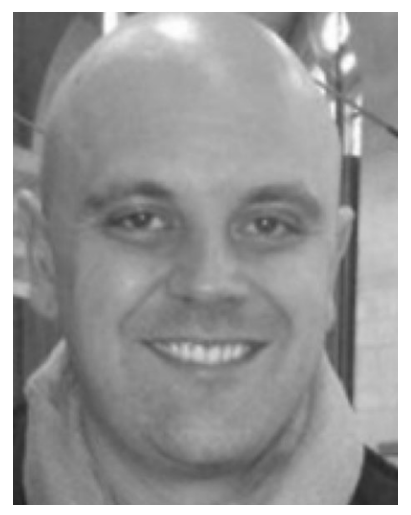

Vincenzo Stornelli was born in Avezzano, Italy. He received the "Laurea" degree (cum laude) in electronic engineering in 2004. In October 2004, he joined the Department of Electronic Engineering, University of L'Aquila, L'Aquila, Italy, where he is involved as Associate His research interests include several topics in computational electromagnetics, including microwave antenna analysis for outdoor ultrawideband applications. He serves as a reviewer for several international journals and Editor of the Journal of Circuits, Computers and Systems. 